\title{
Assessment of Brain Monoaminergic Signaling Through Mathematical Modeling of Skin Conductance Response
}

\author{
Saša Branković \\ Clinic for Psychiatry, \\ Clinical Center of Serbia, Belgrade \\ Serbia
}

\section{Introduction}

The majority of mental disorders (schizophrenia and other psychotic disorders, mood and anxiety disorders) have become treatable for the last several decades mostly due to development of the agents which modulate function of the brain dopaminergic, noradrenergic, and serotonergic system. The art of pharmacological healing in psychiatry consists actually in a great part in choice of the monoaminergic agent (i.e. antipsychotic or antidepressant) or their combinations which will modify the brainstem monoaminergic systems in an appropriate way. In other words, a daily problem in psychiatric practice could be realized as the task of estimation of the actual "neurochemical status" of the patient mostly in respect to the three brainstem monoamines. In clinical setting the task is still accomplished relying on the clinical picture and identifying the dominant symptoms that the patient manifests (e.g. Nutt, 2008; Nutt et al., 2007).

The search for biological correlates (biomarkers) of neurochemical processes associated with mental disorders has not yet resulted in convincing and applicable findings (Bartova et al., 2010; Mössner et al., 2007). A reason that may account for the fail could be that attempts that have been made had been focused on a single neurotransmitter activity (Mössner et al., 2007). On the other hand, "Models which postulate too little or too much of a single neurotransmitter are not consistent with the complex regulation of neurotransmitter systems... There are major functional interactions among different neurotransmitter and neuropeptide systems which make single neurotransmitter theories simplisti A task for future investigations... is to develop clinically applicable biological tests that can assess the functional interactions among different neurotransmitter and neuropeptide systems and specific brain structures. Successful development of such paradigms could result in improved diagnostic classification and prediction of treatment response..." (Charney et al., 1995).

In our interpretation of the task set by Charney \& colleagues "functional interactions among different neurotransmitter and neuropeptide systems" are viewed as neurobiological signals in control system theory meaning of the word 'signal'. With this interpretation the task appear to be "to develop clinically applicable biological tests" which will allow insight into 
the signal interactions among neurotransmitter systems. It means that we are interested in the signal properties of neurotransmission such as: strength of the signal, frequency of signal oscillations, signal amplification and integration, and feedback regulation of the neural signals. Although these signal properties are realized through chemical and electric neuronal activities our methodological approach is not based on the measurements at that level of the neurochemical events. Instead of direct measuring concentrations of released neurotransmitters, density, affinity, and activity of their membrane receptors and reuptake transporters we suggest a method that needs a shift in the perspective of looking at the brain neurochemistry. The twist is that we firstly examine signal processing and control system aspects of a relatively defined neurobiological mechanism. Then, informed with the system and the signals' properties we are able to infer about the underlying neurochemical activity of the involved neurotransmitter systems. In other words, we aim to estimate "interactions among different neurotransmitter and neuropeptide systems" looking at the signal processing in the examined neurobiological mechanism.

The method which enables to examine the underlying regulatory pattern and points to the way of signal processing during a neurobiological process is a mathematical tool, the system identification theory and technique (Ljung, 1999). As a neurobiological mechanism which is convenient for our task to reveal neurochemical signal processing involving the brain dopaminergic, noradrenergic, and serotonergic system we have employed an output of the process of emotional arousal, the phenomenon of emotional, palmar sweating measured as the skin conductance response (SCR), which is regarded as the most useful laboratory test for an autonomic response (Damasio, 1994).

The so-called electrodermal activity (EDA) was discovered at the end of the XIX century as two different phenomena which occur at the palmar and plantar skin surface. One is electrical resistance of the skin surface (Vigoroux, 1879, 1888) and its momentary decreases in response to variety of external stimuli (Féré, 1888). This phenomenon implies passing a small electrical current on the surface of the skin. The other phenomenon is a measurable electrical potential between two electrodes placed on the skin without applying an external current (Tarchanoff, 1890). Contemporary researchers use predominantly the first phenomenon as the method of choice whereby resistance is expressed as its reciprocal - conductance. From the earliest publications the tonic-phasic distinction in EDA has been implied. More about the phasic component speak other terms which have been used to refer to the EDA phenomena in the history, galvanic skin response (GSR), and psychogalvanic reflex (PGR). The phasic component of EDA is nowadays assigned as skin conductance response (SCR) as opposed to the tonic component of EDA which is referred to as skin conductance level (SCL).

Fluctuations in SCL occur at the time-scale of minutes while phasic SCRs appear at the timescale of seconds. Both SCL and SCR activity refer to the activity of palmar and plantar sweat glands and myoepithelial cells of their ducts which are under neural control of the sympathetic branch of the autonomic nervous system (Dementienko et al., 2000). Palmar and plantar sweat glands are not involved in the process of thermoregulation until the ambient temperature does not exceed $30^{\circ} \mathrm{C}$ (Andreassi, 1989; Venables \& Christie, 1980). On the other hand, palmar and plantar sweating is elicited by psychic, emotional stimuli.

The SCR is a sensitive measure, it could be evoked applying weaker psychic stimuli than it would be necessary for other physiological variables (e.g. heart rate, blood pressure, 
respiration, electromyography) (Lader, 1980; O'Gorman, 1971). We suppose that dealing with weaker emotional stimuli put more lights on usual everyday-life emotional responding and arousal fluctuations, a range where individuals with a mental disorder (e.g. depression) are altered presumably due to the alterations in the brainstem monoaminergic systems' activity. The second reason for choosing SCR as a neurobiological mechanism for system identification is continuous nature of the SCR signal. From mathematical point of view, heart rate and respiration rate are derived variables that cannot be computed for time periods shorter than beat-to-beat and respiration-to-respiration period. Therefore, they are to greater extent discreet and so less convenient, since less informative for analysis than a continuous biological signal such as SCR.

The goals of this chapter are: (1) to introduce the reader with the method of system identification of the SCR, (2) to point to the emerging metrics of the SCR process, and (3) to show how this metrics allow inferring about tonic and phasic functions of the brain monoaminergic signaling and about the central neural events - neural input for the SCR system. ${ }^{1}$

\section{Mathematical model of the SCR process: A series of integrations with three feedback loops}

System identification approach enables to look into the process of the SCR in a neurophysiologically meaningful way. Through this method we approximate the whole arousal process (from the initial central neural event to the SCR output) as a series of integrators, with the integration constant of $100 \mathrm{~ms}$, which corresponds to the temporal scale of brain neural integrations (Varela et al., 2001; Koch et al., 1996; Koch, 2005). Knowing the dynamic model of the SCR process enables further examination of the neurochemical meaning of the system parameters and eventually association of the identified regulatory signals with the activity of specific neurotransmitter systems.

\subsection{Solution for the "hidden input" problem in the SCR modeling}

The prerequisite for the system identification procedure which is performed using the System Identification Toolbox included in the mathematical software MATLAB ${ }^{\circledR}$ is that both output and input signal of the system are known. But, while the output signal of the SCR system is observable and measurable, the input signal is not directly measurable. Therefore, a separate scientific task is to find an appropriate mathematical representation of the driving input to the SCR system, i.e. to solve the "hidden input" problem.

A hint to visualize the initial forcing event in the SCR process came from mathematical dealing with differential equations with discontinuous forcing functions: the highest derivative of the solution appearing in the differential equation has jump discontinuities at

\footnotetext{
${ }^{1}$ There is an aspect of the present approach which we want to point out. Many findings and concepts developed in neuroscience during the last two decades have not yet been operationalized for clinical use. The method which is presented here could contribute to lessen this gap translating some concepts of modern neuroscience and making them visible in everyday clinical work. The following concepts are involved: tonic and phasic function of neurotransmitters, gain modulation of neural activity by monoaminergic inervation, feedback regulation in the arousal process, resonance and frequency characteristics of neural systems, central neural code, and signal-to-noise ratio of neural signals.
} 
the same points as the forcing function, but the solution itself and its lower derivatives are continuous even at those points (Boyce \& DiPrima, 2001). Considering the SCR as an output (solution) of a serial integration (in both mathematical and neurophysiological (computation) meaning of the word) and having in mind this simple mathematical rule we assumed that a hidden neural input left its trace and had a fingerprint on the highest derivative of the SCR signal.

Indeed, an inspection of the SCR signal and its derivatives reveals that while the SCR signal and its first two derivates appear to be continuous, jump discontinuities features the third derivative of the SCR signal. This observation suggested that we could be able to read the traces of the discontinuous forcing function (the hidden input) in the third derivative of the SCR signal. The task is to determine an approximation of the unmeasured input signal looking at its fingerprints on the third derivative of the SCR (Figure 1). We approximated the hidden inputs with series of impulses and square pulses. The timing and duration of the pulses have been determined according to the jump discontinuities of the third derivative of the SCR signal. We also exploited the possibility to quantify the strength of the hidden input through measuring the magnitudes of these jump discontinuities. The height of the putative input pulses (the strength of the hidden neural input approximations) has been determined according to the height of the jump discontinuities of the third derivative of the SCR signal.

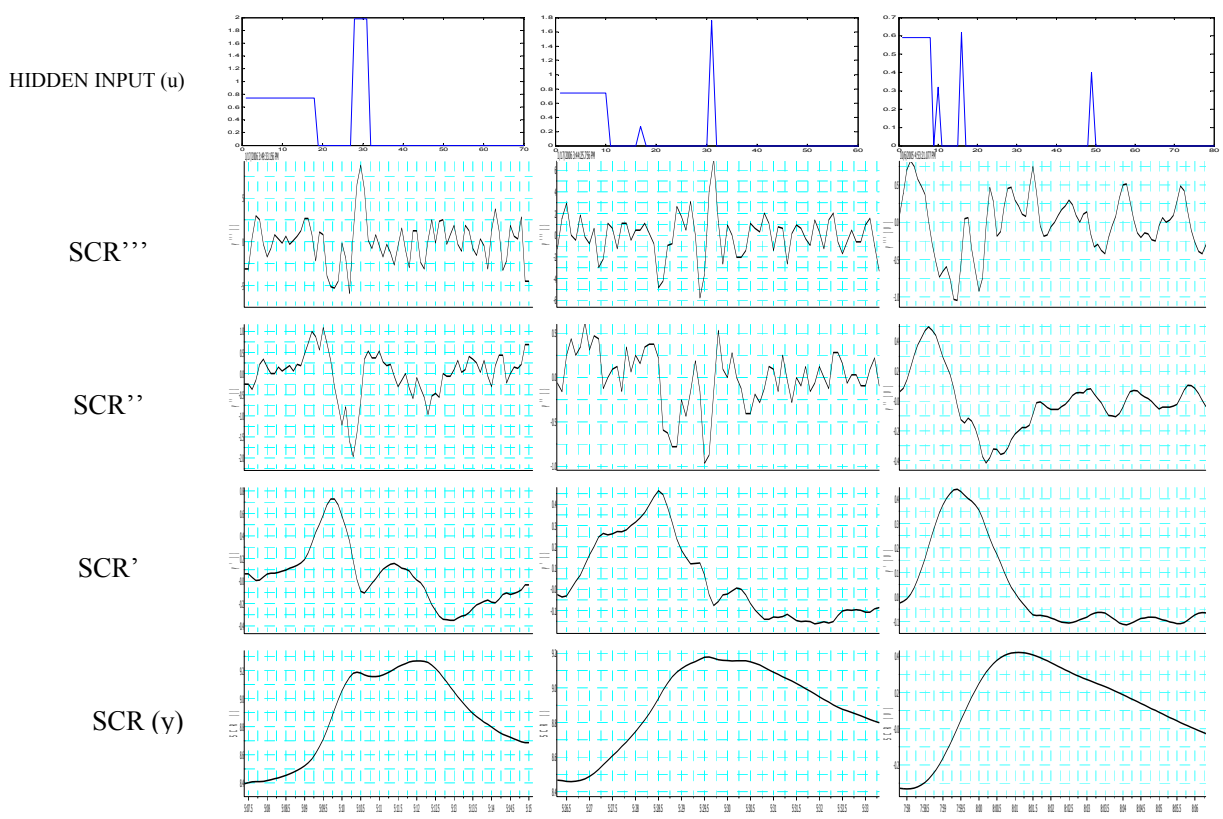

Fig. 1. Hidden-inputs to the SCR system determined observing the jump discontinuities in the third derivative of the SCR signal (SCR'”). Left column: the hidden-input consisting of two pulses of different strength and duration. Middle column: the input consisting of an initial pulse and two impulses of different strength. Right column: the input consisting of an initial pulse and three impulses. 
The method showed simple to be performed and happened to be crucial for the feasibility and accuracy for the system identification approach to SCR. It enables easily obtaining almost perfect fit (>97\%) between measured SCR and the corresponding simulated model's output. Recently we have automated the graphical procedure of estimating the neural input for the SCR system through a program application in the MATLAB ${ }^{\circledR}$ software environment (which will be available online at www.psychophysiological-computation.com and www.psychophysiological-computation.info). The tool could be regarded as a "temporal microscope" for the neural signals which had initiated the recorded SCRs (cf. Tyler \& Likova, 2011).

\subsection{Positive and negative feedback loops drive the SCR to pleasant emotional stimuli}

System identification of the SCRs to pleasant emotional stimuli (textual fragments of short stories, see Subjects and Methods in Branković, 2011) has been performed using the System Identification Toolbox v. 6.0 included in the mathematical software MATLAB ${ }^{\circledR}$ v.7.0 (R14). We defined the model structure and set the fixed parameters and nominal (initial) values of the free parameters that enabled successful system identification of the SCRs to pleasant emotional stimuli for 27 healthy volunteers in the sample (see Subjects and Methods in Branković, 2011). The third-order state-space model appeared to be appropriate for two reasons. First, it yields accurate mathematical modeling of SCR providing high fit $(>97 \%)$ between measured and simulated outputs, and second, it does it in a reliable, robust way, guarantying solution, convergence of the software algorithm dealing with the great variety of SCR input-output data.

Through the system identification procedure we estimate the parameters of the state-space models, which correspond to the coefficients in the equivalent linear differential equation of the system:

$$
y^{\prime \prime \prime}+a \cdot y^{\prime \prime}+b \cdot y^{\prime}+c \cdot y=m \cdot u(t)
$$

That enables us to regard the process of emotional arousal as an interaction among the following signals: 1) neural input to the SCR system, i.e. $u(t), 2)$ the third derivative of the SCR signal $\left.\left(y^{\prime \prime \prime}\right), 3\right)$ the second derivative of the SCR signal $\left.\left(y^{\prime \prime}\right), 4\right)$ the first derivative of the SCR signal $\left(y^{\prime}\right)$, and 4) the SCR signal itself $(y=S C R)$. Graphical representation of the interactions is shown in Figure 2.

Through modeling of over thousand SCRs to pleasant emotional stimuli we were consistently encountering the same resulting feedback structure: the fast positive feedback loop (occurring early in the feedback scheme), the negative (in the middle), and the slow positive feedback loop (originating at the peripheral end of the regulatory chain in the SCR process) ${ }^{2}$.

\footnotetext{
${ }^{2}$ Interlinked positive and negative feedback loops have been identified in many biological systems as the key regulatory scheme (Tsai et al., 2008; Brandman et al., 2005; Brandman \& Meyer, 2008). The wide occurrence of dual-time (fast and slow) positive feedback loops combined with a negative feedback loop has motivated investigations of properties and functions of that regulatory motif during the last decade. Mathematical simulations revealed that such coupled feedback circuits enable systems in noisy environment to produce perfect responses with respect to response duration and amplitude. The dualtime switch, consisting of interconnected fast and slow positive feedback loops, has been suggested as a
} 
S TIMULUS

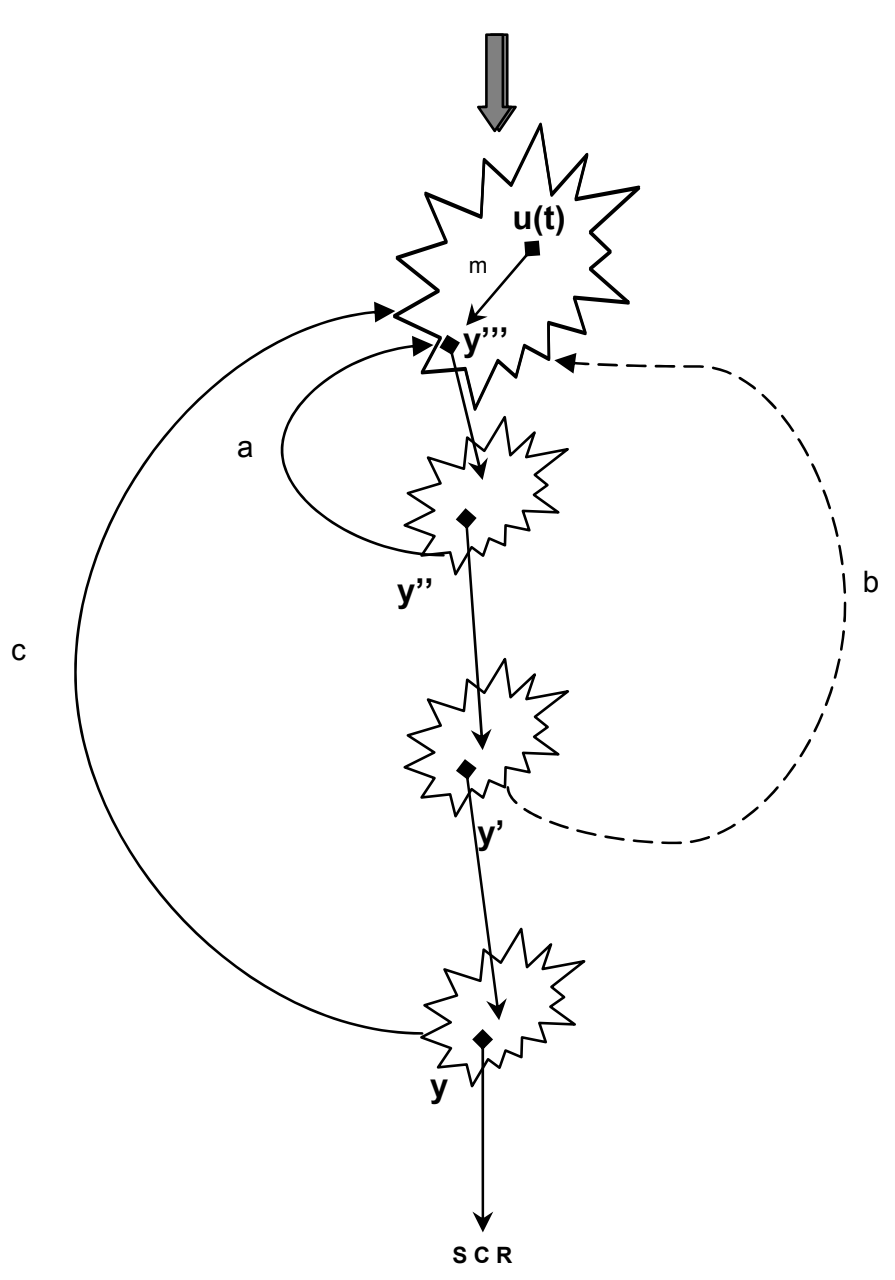

Fig. 2. State-diagram for the mathematical model of the skin conductance response (SCR): $\mathrm{y}^{\prime \prime \prime}+\mathrm{a} \cdot \mathrm{y}^{\prime \prime}+\mathrm{b} \cdot \mathrm{y}^{\prime}+\mathrm{c} \cdot \mathrm{y}=\mathrm{m} \cdot \mathrm{u}(\mathrm{t}) ; \mathrm{y}=\mathrm{SCR}$

ubiquitous regulatory motif performing sensitive robustness in biological systems (Zhang et al., 2007). The foremost activated positive feedback rapidly induces the "on" state transition of the signaling system, the delayed positive feedback robustly maintains this "on" state, while the negative feedback reinstates the system in the original "off" state, prevents excessive response due to multiple positive feedback loops, and suppresses noise effects (Kim et al., 2006; Pfeuty \& Kaneko, 2009) 


\subsection{Emerging metrics of the SCR process}

Since our mathematical dealing with the SCR process encompasses two steps - revealing the hidden input and system identification of the SCR - the approach yields to two sets of parameters. One set includes parameters which characterize the hidden initial neural input to the SCR system. The other set consists of parameters which characterize the SCR control system itself (Branković, 2011).

\subsubsection{The hidden-input metrics}

Through the graphical solving of the hidden input problem, relying on the jump discontinuities of the third derivative of the SCR signal (see 2.1), we approximated the initial neural event in the SCR process with series of impulses and square pulses (see Figure 1). The method enables quantification of the four features of the hidden input. In other words, we can define four dimensions in the hidden-input metrics: 1) number of pulses in the hidden input, 2) the amplitude (height, strength) of the pulses, 3) duration of the pulses, and 4) timing of the pulses (e.g. inter-pulse interval). This forms the hidden-input metrics.

The count of pulses in a hidden-input in our sample varied from 1 to 6 . The amplitude of the pulses was in the range 0.023-7.74. The duration of the pulses in the hidden-inputs varied in the interval 0.1-2.8 s. The inter-pulse interval in the hidden-inputs was in the range 0.1-3.5 s.

Exploration of the within-subject distribution of values of the described hidden-input measures revealed normal distribution of pulse duration and log-normal distribution of pulse amplitude ${ }^{3}$ (Figure 3).

\subsubsection{System parameters of the SCR process}

The set of the parameters which refer to the regulatory or control system aspect of the SCR process is composed of: input gain, fast positive feedback loop gain, negative feedback loop gain, slow positive feedback loop gain, static system gain, and fidelity period (Branković, 2011).

Input gain. This parameter corresponds to the constant " $\mathrm{m}$ " in the differential equation of the system. It reflects the initial step in the process of the regulation of emotional arousal. We have found the range of values $0.0013-0.025$ for this parameter.

Fast positive feedback loop (FPFL) gain. Of the three feedback loops in the model (Figure 2) the first is proportional to the second derivative of the SCR signal ( $\left.y^{\prime \prime}\right)$ and it is positive. We denote the parameter that characterizes this feedback loop as fast positive feedback loop gain. It equals the constant "-a" in the differential equation of the system. The found range of values of this parameter in healthy subject is $2.61-2.83$. The within-subject coefficient of variation of this fast enhancement is about $1 \%$.

Negative feedback loop (NFL) gain. The second feedback loop in our model is proportional to the rate of change of the emotional arousal $\left(\mathrm{y}^{\prime}\right)$ and it is negative. It reflects a feedback inhibition in the arousal process. The parameter that characterizes this feedback inhibition equals the constant " $-b$ " in the differential equation of the system. The found values of this

\footnotetext{
${ }^{3}$ It is interesting that within-subject variations of the pulse amplitudes sometimes manifested quantal nature (i.e. different values relate as integer multiplications to each other) (see Figure 3).
} 
parameter are in the range from -2.44 to -2.68 . The within-subject coefficient of variation of the inhibition loop in the SCR model is about $3 \%$.
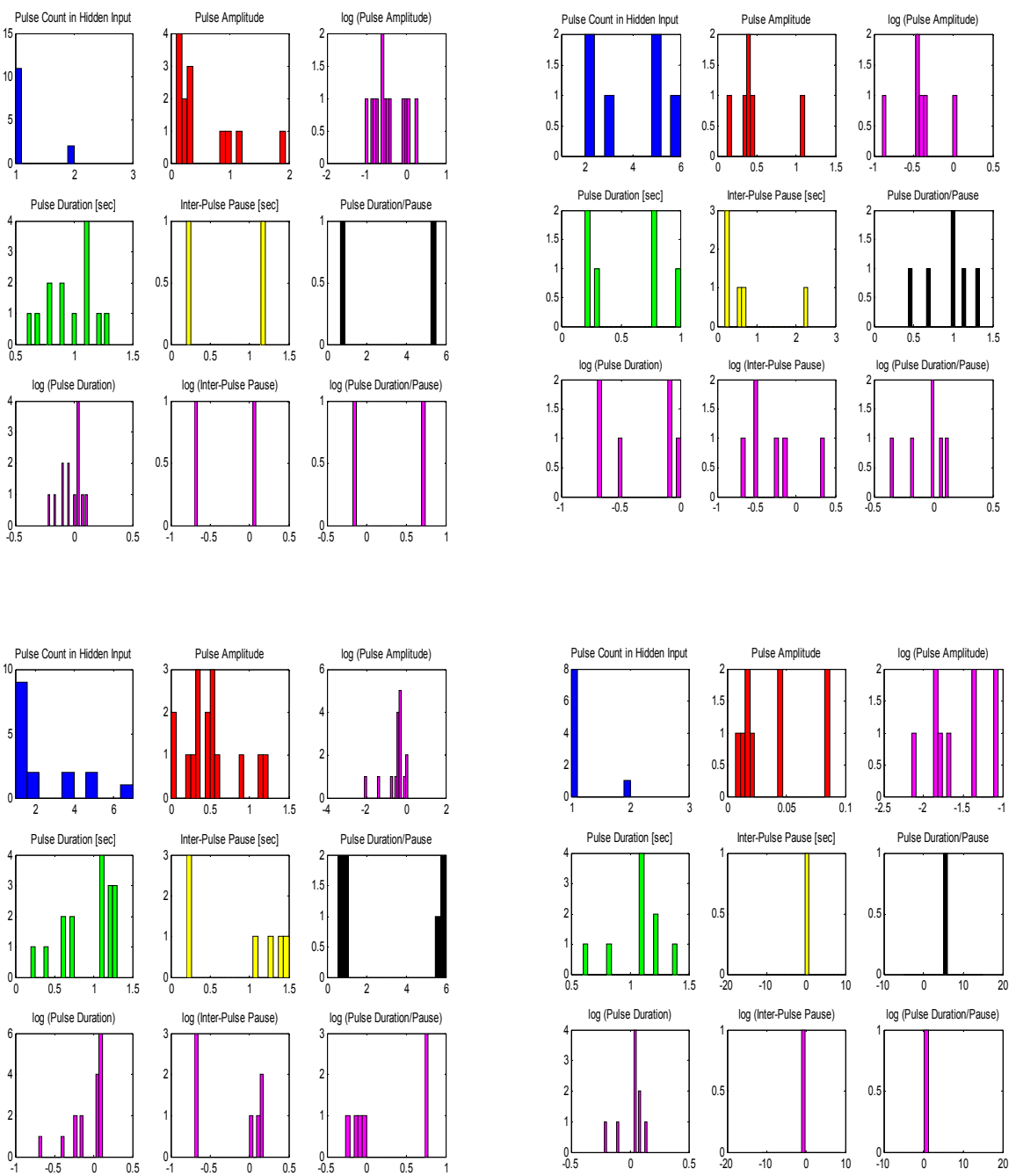

Fig. 3. Within-subject distributions of the hidden-input measures of four different subjects

Slow positive feedback loop (SPFL) gain. The third feedback loop in the model is proportional to the actual level of the emotional arousal, actual value of the SCR signal (y) and it is positive. The parameter that characterizes this feedback enhancement equals the constant "- $c$ " in the differential equation of the system. The found range of values of this feedback loop gain is $0.65-0.86$. The within-subject coefficient of variation of the slow enhancement is about $5 \%$. 
Static system gain. The value of low frequency or static system gain of linear time-invariant system can be obtained as a direct result of the MATLAB ${ }^{\circledR}$ function "dcgain". The values of the system gain in our sample are $1.13-48.57$.

Fidelity period. Some but not all models of the SCRs to pleasant emotional stimuli show potential for resonance. That is why we can not use resonant frequency as a parameter to characterize the all SCR models. Instead, we use the time period of periodic stimulation when the amplitude of response drops $3 \mathrm{~dB}$ below (or to $70.7 \%$ of) its zero-frequency value (amplitude of response which appears responding to a single stimulus). Expressed in seconds, fidelity period has a psychological meaning and face validity. Namely, with a further shortening of the inter-stimulus period in comparison with the fidelity period the amplitude of the SCR is rapidly diminishing. In that way, fidelity period gives an indication of the noisefiltering characteristics of the system. The found value of the fidelity period in our sample of the SCR models is about 13 seconds. ${ }^{4}$

Exploration of the within-subject distribution of values of the described system parameters revealed normal distribution of the three feedback loops' gains and fidelity period, and lognormal distribution of input gain and overall static system gain (Figure 4). The high intra-trial reliability of the estimations of the feedback loop gains (coefficients of variations: 1-5\%) points to the reliability of measurement of these parameters.

\section{The mathematical model of the SCR in the context of neurobiological data}

The stereotyped nature of the SCR waveform has recently inspired several dynamic modeling approaches to the process of SCR. The published models differ in the neurobiological interpretation of the system's parameters. While several research groups consider the peripheral sympathetic sudomotor nervous signal as the impulse input in their models of the SCR (Alexander et al., 2005; Bach et al., 2009, 2010a, 2010b, 2011; Benedek \& Kaernbach, 2010), we assumed that the initial neural event and feedback regulatory mechanisms that we could comprise with our models took place in central brain structures (Branković, 2008). In the last case we would be able to derive much more information about the central neural processing from the SCR signal than we used to do, and, what is even more important, to infer about the brain mechanisms in a way that is not achievable by any other available method including invasive ones.

\subsection{Evidence for the brain mechanisms involvement in the SCR model}

We have recently found (Branković, 2011) that different types of SCRs (orienting response, SCR to pleasant emotional stimuli, weak movement, and respiratory SCR) have distinct regulation (i.e. different system parameters). This finding raises the question of adequacy of the assumption that mathematical models of the SCR process describe the sudomotor innervation and sweat gland activity (Alexander et al., 2005; Bach et al., 2009, 2010a, 2010b, 2011; Benedek \& Kaernbach, 2010). The doubt has been recently expressed by Bach and

4 The estimation of the duration of fidelity period of the SCR system in our sample corresponds well to the empirical data on breaking values of the interstimulus interval in the SCR measurement research (Breska et al., 2011; Benedek \& Kaernbach, 2010). 

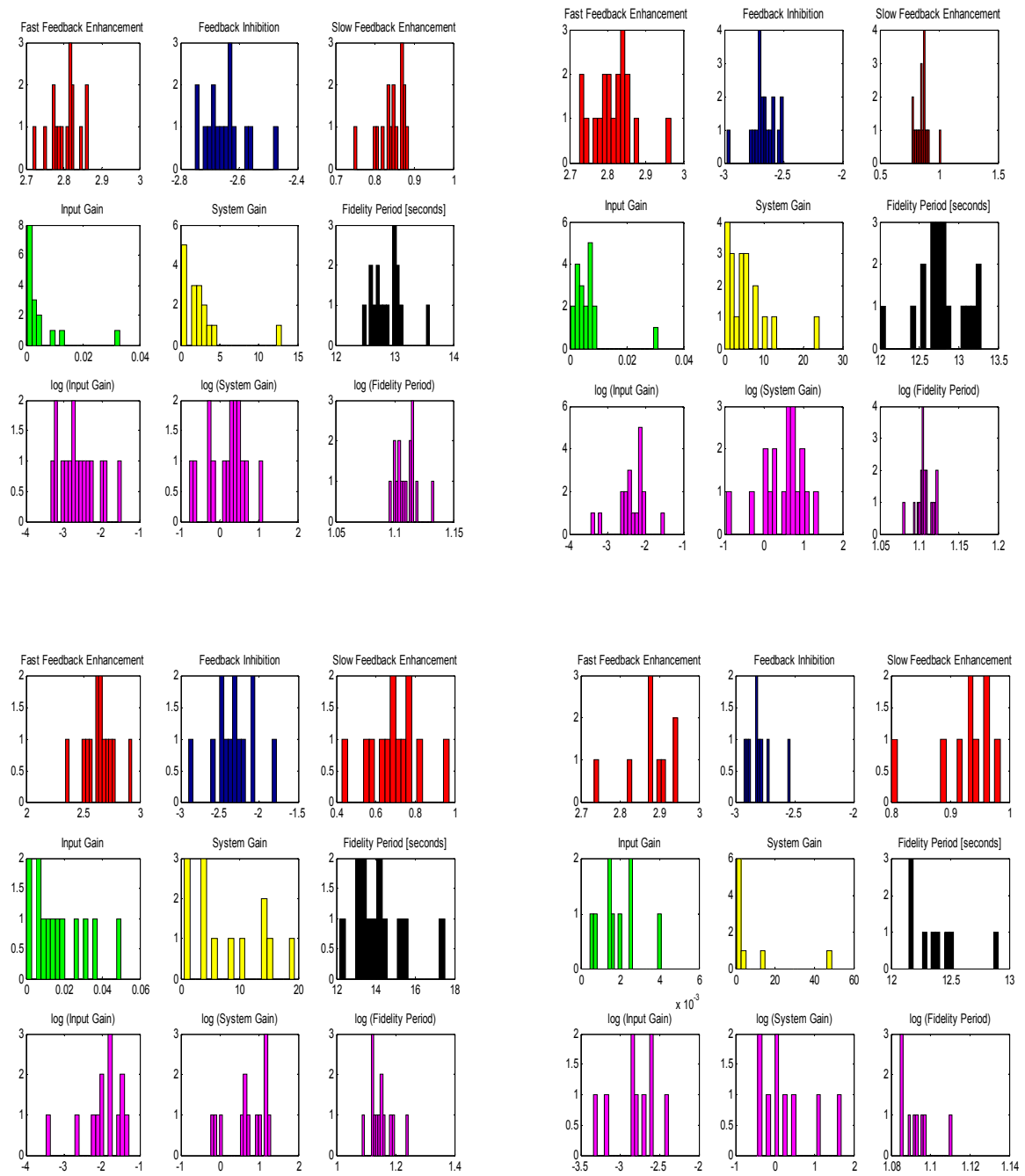

Fig. 4. Within-subject distributions of the SCR system parameters of four different subjects

colleagues (2010b) who found a difference of SCRs evoked by aversive pictures in comparison with other applied stimulus classes: "There is no reason why the peripheral output system should exhibit a different response to one stimulus class than to any other... The twist is that it might be possible to estimate characteristics of central nervous function by deconvolving the observed signal." Yet, the spark of this view we can trace back in the Edelberg's work on the so-called recovery limb of the SCR four decades ago. Edelberg (1970) proposed that rapid- and slow-recovery SCRs reflect qualitatively different psychological processes as a result of distinct neural control. 
Different types of SCR lend support for the central interpretation of the identified model of the SCR process. This view has potentially significant implications. Namely, it follows that metrics of hidden-input and feedback loops in the SCR process could refer to the brain neurocircuitry and neurochemistry rather than to the biophysical properties of the sweat glands.

The shift from peripheral to central interpretation of the mathematical models of SCR challenges our understanding of the physiological nature of the SCR. Does the phasic electrodermal response reflect sweat secretion, passive diffusion, and reabsorption process? It would be difficult to explain precise influence and transmission of the central neural events on the distinct, stimulus specific SCR form if it would be realized through sluggish processes such as secretion, diffusion, and reabsorption. But there is evidence that formation of SCR could be better explained as determined by constriction of myoepithelial cells of ducts of the sweat glands (associated with vasomotor activity) on activation of the sympathetic nervous system than by long-time secretion, spreading and reabsorption of secretion (Dementienko et al., 2000).

\subsection{Putative scenario of neural computations during the SCR process}

Considering the results of the system identification studies of SCR (Branković, 2008, 2011) in the context of the data regarding the functional neuroanatomy of the SCR and emotional processing we suggest the following scenario during the process of generation and regulation of SCRs to pleasant emotional stimuli.

The initial step (generation of the initial neural event, i.e. the input neural signal for the SCR system) takes place in the interaction amygdala-hippocampus: "Outcome of the specific patterning of the match-mismatch process in the hippocampus/amygdala complex determines the precise constellation of signals to be either routed onward to the hypothalamus or aborted, and shapes the affective response or lack thereof to any stimulus event" (Hadley, 1989, p. 346; Laine et al., 2009; Phelps, 2004). In the amygdala-hippocampus interplay the role of the hippocampus is to detect novelty and unexpectedness of the stimulus (Kumaran \& Maguire, 2007a, 2007b, 2008; Vinogradova, 1975). On the other hand, 'attachment of significance [emotional meaning] to a stimulus is critically dependent on the amygdala" (Mishkin \& Aggleton, 1981, p. 412). We assumed that only unexpected pleasant emotional stimuli could elicit initial neural signal for pleasant emotional excitement (measured as the SCR) (Branković, 2001).

It is tempting to hypothesize that some features of the hidden-input to the SCR system could refer to novelty (or unexpectedness) aspect of the stimulus and some other hidden-input measures to significance (or emotional meaning) of the stimulus. It has been already suggested that different features of stimuli were represented through different dimensions of the neural pulse code in one neural system (Masuda \& Aihara, 2007). Also, it has been realized that the neural code refers to population activity since individual neurons could not provide sufficient signal-to-noise ratio and speed to transmit information (Lestienne, 2001; Shadlen \& Newsome, 1998; Eggermont, 1998). Relying on these findings we suggest that the dimension 'pulse amplitude' in our hidden-inputs metrics could correspond well to the 'population firing rate code' of the neural signal (Masuda \& Aihara, 2007). Duration of the pulses in the hidden-input metrics fits the burst duration code (Kepecs \& Lisman, 2004). 
Finally, temporal distribution of the pulses in the 'hidden-input for the SCR' could refer to the temporal neural code (e.g. inter-burst interval) (Lestienne, 2001). Further work should be done to explore the statistics and semantics of the 'hidden-input code'. Probably, the neural code of the amigdalohippocampal circuit converts some subjective features (estimations) of stimuli ("stimulus attributes arrived at by computational process", and not physical attributes of stimuli (Eggermont, 1998)) into emotional (sympathetic) response. In other words, different dimensions of the hidden-input metrics could relate to different features (e.g. novelty vs. intensity (Barry, 2006)) of the stimulus that evokes the SCR.

The amigdalo-hippocampal interplay (resulting in the generation of neural input for the emotional SCR) is probably realized through the rhythmic, theta-related $(5-11 \mathrm{~Hz})$ modulation of neuronal activities in the amigdalo-hippocampal circuit which may provide adequate recurring time windows when synaptic interaction will be facilitated in this limbic network (Seidenbecher et al., 2003; Paré \& Gaudreau, 1996). The theta selfsynchronization of hippocampal and amygdala neurons (suggesting functional connectivity between those neurons) is not continuous but periodic process, which occurs both spontaneously every 5-30 seconds (mean $12.9 \mathrm{~s}$ ) in brain slices maintained in vitro (Kano et al., 2005) and confronted with emotion-inducing stimuli (Pape et al., 2005; Seidenbecher et al., 2003). Interestingly, the periodicity of the amigdalo-hippocampal theta synchronization fits well with the fidelity period of the emotional SCR system about 13 seconds (see 2.3.2). Moreover, the periodic theta amigdalo-hippocampal neural synchronizations last up to 2.5 seconds (Kano et al., 2005) what corresponds to the duration of the hidden-input pulses for the emotional SCR (see 2.3.1).

Along with the large amplitude theta synchronous oscillations both amygdala and hippocampal neurons generate action potentials at $24-45 \mathrm{~Hz}$ during the initial component of the periodic amigdalo-hippocampal synchronization (Kano et al., 2005). We speculate that postsynaptic integration of this early high frequency component of synchronous periodic events could be responsible for the strength (amplitude, height) of the "hidden" neural input for the emotional SCR (see 2.3.1). With this ends the first phase in the SCR process generation of the neural input (the trigger of the emotional response).

The next phase is transmission and regulation of the SCR. This phase is realized through bidirectional connections among amygdala, hypothalamus, and the brain stem (cf. Pfaff, et al., 2005). In his neurobiological model of emotion regulation Lewis (2005) emphasized multiple positive and negative feedback components originating from brain stem which back up to amygdala and other cortical and subcortical systems increasing the activation of some systems while decreasing it in others. In the identified (central) control process of the SCR we detected three feedback loops (see 2.3.2). According to the known neurobiology of arousal the first candidates for the neurochemical substrate of the feedback loops could be brainstem originating monoaminergic inervation of amygdala and hippocampus: i.e. dopaminergic, noradrenergic, and serotonergic system. ${ }^{5}$

\footnotetext{
5 "The activation of structures at different levels of the neuroaxis drives the brain into vertical integration. Reciprocal influences among brain stem, hypothalamic, and corticolimbic regions become coupled, perhaps through synchronization of independent oscillators, and this coupling may give rise to an emergent meta-synchronization that coordinates all lower-order couplings" (Lewis, 2005, p. 192).
} 


\section{Revealing the neurochemical meaning of the parameters in the model of the SCR process: Foundation for the psychophysiological probing of brain monoaminergic signaling}

Considering the neurochemical meaning of the system parameters in the SCR model (e.g. feedback loops' gains) the following important issue should be clarified. Although the nodes in our dynamic model (Figure 2) could be realized as principal points on the path of integration and feedback regulation of the central neural signal conveying the information for emotional sweating we do not expect that the SCR signal which we measure at the skin surface and which figures as the slow positive feedback loop in the SCR model is actually transmitted back to the brain through some receptors and ascending neural pathways and takes part in the regulation of arousal. Rather, we suppose that in the central regulation of the arousal appears some neural signal (we assume a brain stem monoaminergic activity) with the similar and coherent temporal characteristics as the measured SCR which is the real slow positive feedback signal in the process of the SCR. ${ }^{6}$ We hold the similar view on the fast positive feedback signal and the negative feedback signal in our SCR model. Mathematically they appear as the first and the second derivative of the measured SCR signal but neurobiologically they correspond to two earlier nodes in the neural integration chain during the SCR process.

Keeping in mind this notion we are equipped with a broader and more flexible perspective which could yield to a more accurate identification of the neurochemical meaning of the SCR system parameters than it would be the case if we would persist in trying to find real neuroanatomical pathways which convey the SCR signal (which we measure) back to the brain.

In order to reveal neurochemical meaning of the parameters obtained through mathematical modeling of the SCR process we have conducted a psychopharmacological intervention study. The basic idea had been to detect and follow the changes in the SCR system parameters in psychiatric patients receiving medication with well defined influence on certain brain neurotransmitter systems. The idea corresponds to that what Humble (2000) has assigned as "the psychopharmacological dissection". Although antidepressant exerts neither a single neurotransmitter effect nor a single action on a neurotransmission system (Leonard, 2000) there are differences among them. They differ in selectivity for both reuptake inhibition and receptor blockade. Among the most selective drugs for "the psychopharmacological dissection" are citalopram (the purest serotonin reuptake inhibitor available), reboxetin (the purest noradrenaline reuptake inhibitor), and maprotiline (which exerts considerably more receptor-blocking activity but also less inhibition of serotonin reuptake than other noradrenaline reuptake inhibitors) (Humble, 2000).

In agreement with the thesis that identified control process of SCR takes place in the neurocircuitry located between amygdala and brain stem speaks comparability of spectral characteristics of the signal components of the SCR system (SCR signal, its derivatives, and periodicity of the hidden input) on one side, with dominant oscillatory activity of the brain structures engaged in arousal process in that section of the neuroaxis (Branković, 2011).

${ }^{6}$ Similarity in temporal patterns displayed by a central measure of brain function (the N200 component of event-related potentials) and the measured peripheral SCR signal has been already detected, demonstrating dynamic relationship between the SCR signal and a brain neural process (Lim et al., 1999). 
The neurochemical agents which we used to perform a kind of "the psychopharmacological dissection" of the SCR system were: (1) citalopram (daily dose $20 \mathrm{mg}$ ), a selective serotonin reuptake inhibitor (SSRI) - in revealing the serotonergic components of the SCR system (in 21 depressed patients); (2) maprotiline (daily dose $150 \mathrm{mg}$ ) - in revealing the noradrenergic SCR system's components (in 20 depressed patients); and (3) venlafaxin (daily dose $225 \mathrm{mg}$ ) or clomipramine (daily dose $150 \mathrm{mg}$ ) as dual acting (both serotonergic and noradrenergic) agents (in 18 depressed patients). The patients were diagnosed according to the DSM-IV criteria (American Psychiatric Association, 1994) for major depressive disorder currently in depressive episode. The mean score on the Hamilton (1960) rating scale for depression (HAMD) with 17 items was $21.4(\mathrm{SD}=6.7)$ on the day of the first psychophysiological measurement (the day before starting the pharmacological treatment) with non-significant differences among the treatment groups. All patients manifested significant clinical improvement after four weeks of the inter-trial period assessed as reduction of the HAMD score for more than $50 \%$.

One concept of the modern neuroscience should be mentioned before we continue with the results of the pharmacological intervention study. It deals with the distinction between the tonic and the phasic neurotransmitters' function. We find this distinction essentially for understanding the observed SCR system parameters' change in patients under psychopharmacological treatment. In the following we explain how some of the parameters refer to the tonic and others indicate the phasic function of serotonin and noradrenaline.

\subsection{The hidden-input measures and the brain monoaminergic systems}

According to the suggested scenario of neural computations during the SCR process (see 3.2) two features of the hidden input - pulse amplitude and duration - could be supposed as dependent not only on the characteristics of the encountering stimulus but also on the tonic monoaminergic innervation of the amygdalo-hippocampal circuit. For instance, it was shown that both dopamine agonists and antagonists alter the amygdala response to emotional stimuli (Salgado-Pineda et al., 2005; Takahashi et al., 2005; Exner et al., 2004). It is also known that noradrenaline modulates the filter function in the hippocampus causing an increase in the signal-to-noise ratio of the pyramidal cells such that the cells' response to stimuli near action potential threshold are inhibited, whereas the responses to larger stimuli are enhanced (Nicoll et al., 1987; Segal \& Bloom, 1976).

Comparison between healthy subjects and acutely depressed patients of our sample regarding the amplitude and duration of the hidden-input and inter-pulse interval was performed using the t-test for independent samples with Bonferroni adjustment for multiple tests. The tests revealed significant lower amplitude of the hidden-input in depression and no difference regarding the duration and inter-pulse interval between healthy and depressed participants.

In order to test whether the diminution of the hidden-input amplitude in depression is due to deviant brain monoaminergic function we conducted an intervention study with antidepressants and probed the SCR system of the patients at the three times: 1) the day 0 , i.e. the day before starting the antidepressant treatment, 2) the day 7 , corresponding to the acute antidepressant treatment phase, and 3) the day 28, corresponding to the chronic 
antidepressant treatment phase. We tested the hypothesis that serotonergic and noradrenergic agents influence the process of generation of the initial neural input for the SCR system examining if there is any pattern of change in the amplitude and duration of the hidden-input in depressed patients before and during the treatment with antidepressants. The t-tests for dependent samples (using Bonferroni correction for multiple tests) revealed significant increase of the hidden-input amplitude and prolongation of the input pulse after four weeks of antidepressant treatment considering all applied agents together. The chronic antidepressant treatment did not significantly affect the timing of the pulses in the hiddeninput, i.e. the inter-pulse interval remained unchanged.

In order to test if the monoaminergic agents show distinctive effect on the features of the hidden-input the following multivariate analysis of variance has been performed. We compared the relative change (in percents) of the hidden-input measures in the three groups of patients underwent to three different four weeks treatments: 1) citalopram group, 2) venlafaxin or clomipramine treated group, and 3) maprotiline group. The MANOVA revealed significant difference on the overall model between the treatment groups (Wilks' lambda $=0.463, \mathrm{~F}(6,82)=6.42$, $\mathrm{p}<0.0005$, multivariate eta-squared $=0.32)$. The univariate analyses of variance revealed significant differences among the treatment groups regarding the hiddeninput amplitude (eta-squared $=0.438$ ) and hidden-input duration (eta-squared $=0.143$ ) and nonsignificant differences regarding the inter-pulse pause. Pairwise comparisons revealed a stronger increasing effect on the hidden-input amplitude of the serotonergic agent (citalopram) than it was the case after venlafaxin or clomipramine treatment (Table 1). Interestingly, chronic treatment with maprotiline brought to lessening of the hidden-input amplitude. On the other hand, all three kinds of applied monoaminergic agents brought to prolongation of the hiddeninput pulse but citalopram was significantly less effective than both venlafaxin/clomipramine and maprotiline. The last two kinds of treatment were not mutually significantly different regarding the effect on the hidden-input pulse prolongation.

\begin{tabular}{|c|c|c|c|}
\hline Hidden-input feature & Citalopram & $\begin{array}{c}\text { Venlafaxin/ } \\
\text { Clomipramine }\end{array}$ & Maprotiline \\
\hline Pulse Amplitude & 125.55 & 39.91 & -83.33 \\
Change [\%] & $(19.98)$ & $(22.89)$ & $(30.52)$ \\
\hline Pulse Duration & 6.74 & 36.64 & 41.18 \\
Change [\%] & $(36.64)$ & $(9.98)$ & $(13.31)$ \\
\hline Inter-Pulse Pause & 28.53 & 79.68 & -30.833 \\
Change [\%] & $(30.92)$ & $(35.425)$ & $(42.23)$ \\
\hline
\end{tabular}

Table 1. Effects of a serotonergic agent (citalopram), dual acting agents (venlafaxin or clomipramine), and a noradrenergic antidepressant (maprotiline) on the hidden-input characteristics. The values represent means of the relative change in percents (SD).

\subsection{Tonic and phasic functions of the brain monoaminergic signaling and the SCR system parameters}

Relying on our neurobiological model of the SCR process (see 3.2) it follows that the parameter input gain appears as an indicator of the tonic function of the brain monoaminergic signaling. On the other hand, feedback loops' gains seem to refer to phasic 
functions of the brainstem monoaminergic systems conveying feedback enhancement and inhibition of the central neural signal which controls the output SCR signal.

Of the three feedback loops in the obtained mathematical model (Figure 2) the first one is proportional to the second derivative of the emotional arousal $\left(\mathrm{SCR}^{\prime \prime}\right)$ and it is positive. It refers to some neural signal that backwards enhances the already initiated arousal process. Because of a proximal neuroanatomical position on the amygdala-brainstem axis in comparison with other monoaminergic systems, and similarity of the spectral characteristics of the SCR" and phasic dopaminergic activity (see Branković, 2011) we speculate that the fast feedback enhancement could relate to the phasic dopaminergic activation (Wanat et al., 2009; Redgrave et al., 2008; Lodge \& Grace, 2006; Phillips et al., 2003) and positive feedback regulation of excitability in amygdala neurons through the process of slow afterdepolarization (Yamamoto et al., 2007).

The second feedback loop in the integration chain of our SCR model is negative one. It reflects the feedback inhibition in the arousal process. We speculate that for this feedback inhibition monoaminergic projections to the amygdala coming from the brainstem could be responsible - noradrenergic inhibition from the locus coeruleus (Buffalari \& Grace, 2007; Schätze et al., 1987) and/or serotonergic inhibition from the raphe nuclei acting both directly on projection neurons and on interneurons (Stein et al., 2000; Rainnie, 1999).

One of the major outputs of the amygdala is the pathway from the medial amygdala to the paraventricular nucleus of the hypothalamus (PVN). This projection plays a critical role in expression of the autonomic response to stimulus (LeDoux, 1992). Beside the sympathetic projections of the PVN for the spinal cord, there is another arm of the PVN output that innervates locus coeruleus (LC) both directly (Reyes et al., 2005; Luppi et al., 1995) and indirectly through the innervation of the nucleus paragigantocellularis, which is the main input for the LC (Van Bockstaele et al., 1989; Aston-Jones et al., 1986). The majority of the axons of the PVN that directly innervate the LC release corticotrophin releasing factor (CRF) at their endings (Reyes et al., 2005). CRF activates the LC-noradrenergic system and increases the releasing of noradrenaline at the terminal projecting fields of the system (Dunn et al., 2004). The locus coeruleus does not innervate intermediolateral column of thoracic cord and, hence, is not directly involved in the transmission of the output of the sympathetic system to the periphery (Valentino \& Aston-Jones, 1995; Fritschy et al., 1987). This refers to a different role of the LC activation that could lie in a feedback effect upon the higher brain structures. Indeed, it was shown that the noradrenegic projections from the LC have inhibitory influence on the kindling effect in the amygdala and the hippocampus (Giorgi et al., 2003). Beside that, the neurons in the amygdala that had been inhibited by the stimulation of the carotid sinus and baroreceptors were also inhibited by the stimulation of the LC (Schätze et al., 1987). For these reasons the projections of the hypothalamic PVN that innervate the LC (directly and through the nucleus paragigantocellularis) could be assigned as the regulatory output arm of the PVN.

In order to explore the neurochemical nature of the identified feedback loops and the parameter input gain in the SCR system we performed the following analyses. Comparison between healthy subjects and acutely depressed patients of our sample regarding the input gain and the three feedback loops gains was performed using the t-test for independent 
samples with Bonferroni adjustment for multiple tests. The tests revealed significantly weaker gains in all three feedback loops of the SCR system in depression and also a tendency in depression for lessening of the input gain although the found difference did not reach statistically significant level.

In order to test whether the weakening of the feedback loops' gains in depression is influenced by disturbed serotonergic and noradrenergic brain function we compared the SCR system parameters of depressed patients before, after 7 days, and after four weeks of the antidepressant treatment. The repeated measures MANOVA revealed significant effect for time of treatment (Wilks' lambda $=0.035, \mathrm{~F}(8,51)=175.07, \mathrm{p}<0.0005$, multivariate eta squared $=0.965)$. The univariate analyses of variance revealed significant differences among the treatment phases regarding the three feedback loops' gains and also input gain (Figure 5). Pairwise comparisons (with Bonferroni adjustment for multiple tests) revealed significant strengthening of the feedback loops' gains during four weeks of antidepressant treatment. The applied antidepressants also changed the input gain of the SCR system.
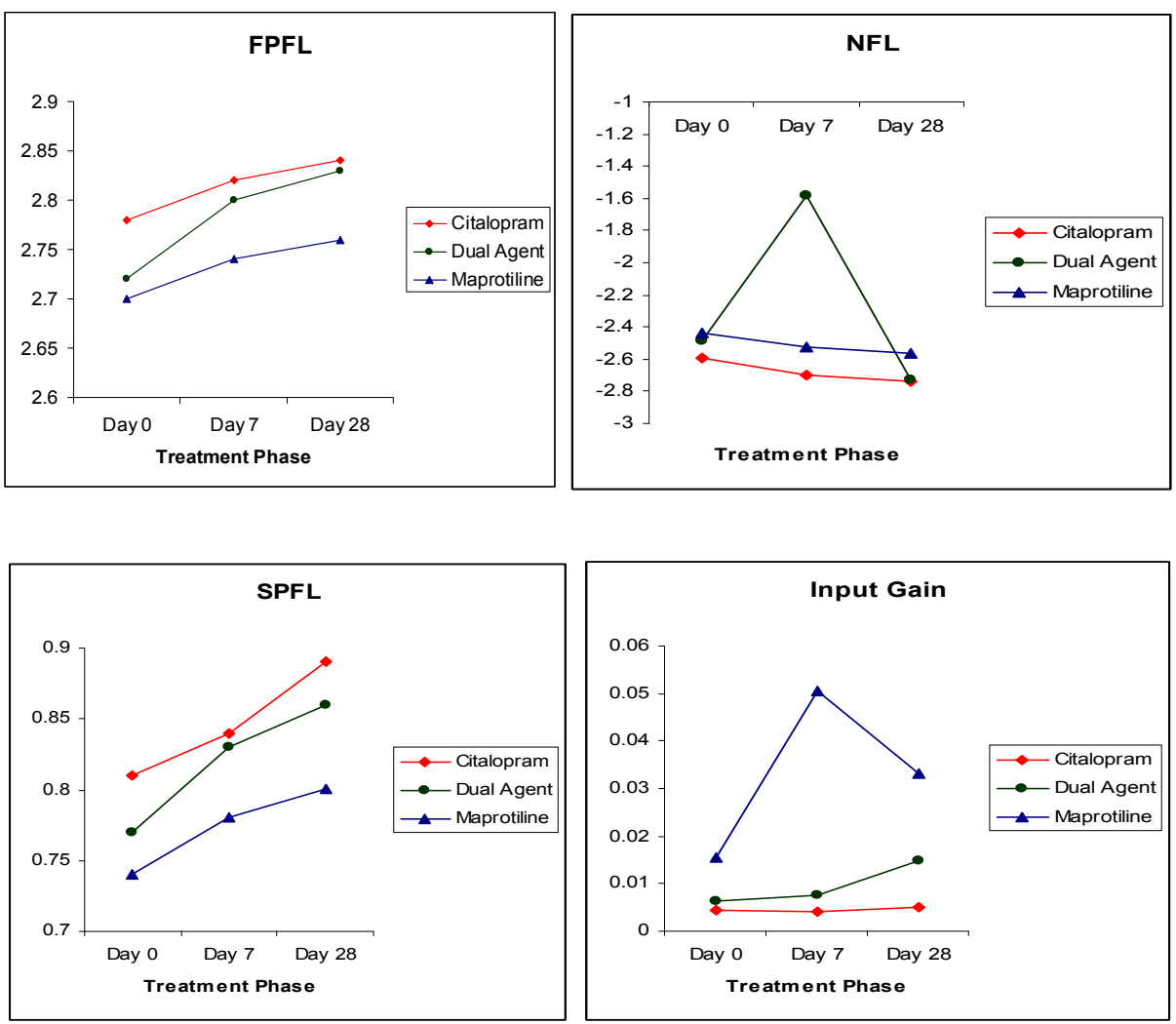

Fig. 5. Change of the SCR system parameters during the antidepressant treatment 
In order to test whether the antidepressants have distinctive effect on the SCR system parameters the multivariate analysis of variance has been performed. We compared the relative increase (in percents) of the feedback loops' gains and of the input gain in the three groups of patients underwent to three different kinds of drug treatment. The MANOVA revealed significant difference on the overall model between the treatment groups (etasquared $=0.379$ ). The univariate analyses of variance revealed significant differences among the treatment groups regarding the all three feedback loops' gains and non-significant differences in respect to input gain. Pairwise comparisons showed a stronger increasing effect of dual acting agents (venlafaxin/clomipramine) on the FPFL and the NFL gains than the effect of citalopram and maprotiline (Table 2). Citalopram and dual acting agents have similar strengthening effect on the SPFL gain and their effect is significantly stronger than the effect of maprotiline. The four weeks treatment with all three kinds of antidepressants was associated with similar increase of the input gain in the SCR system.

\begin{tabular}{|c|c|c|c|}
\hline $\begin{array}{c}\text { SCR System } \\
\text { Parameter }\end{array}$ & Citalopram & $\begin{array}{c}\text { Venlafaxin/ } \\
\text { Clomipramine }\end{array}$ & Maprotiline \\
\hline $\begin{array}{c}\text { Fast Positive Feedback Loop } \\
\text { Gain Increase [\%] }\end{array}$ & 2.61 & 4.01 & 2.49 \\
$(2.12)$ & $(1.82)$ \\
\hline Negative Feedback Loop Gain & $5.79)$ & 9.59 & 4.91 \\
Increase [\%] & $(2.48)$ & $(5.46)$ & $(3.56)$ \\
\hline Slow Positive Feedback Loop & 9.42 & 12.51 & 5.12 \\
Gain Increase [\%] & $(4.01)$ & $(6.73)$ & $(4.25)$ \\
\hline Input Gain Increase [\%] & 37.50 & 83.07 & 117.86 \\
& $(114.58)$ & $(120.11)$ & $(18.37)$ \\
\hline
\end{tabular}

Table 2. Effects of a serotonergic agent (citalopram), dual acting agents (venlafaxin or clomipramine), and a noradrenergic antidepressant (maprotiline) on the SCR system characteristics. The values represent means of the relative increase in percents (SD).

\subsection{Neurochemical meaning of the parameters in the SCR process model suggested by the results}

Relying on the results (summarized in Tables 1 and 2) we suggest the following interpretation of the neurochemical meaning of the SCR model parameters. The finding of the strongest increasing effect of citalopram on the hidden-input amplitude could speak about the serotonergic nature of this hidden-input dimension. Since we assumed influence of the tonic function of the monoaminergic innervation on the strength and duration of the hidden neural input (see 4.1) it follows that the finding of $125 \%$ increase of the hidden-input amplitude after selective serotenergic treatment implicates responsibility of the tonic serotonergic function for this increase. Quantitatively this increase is in agreement with the prediction of the mathematical model of the neurochemistry of serotonin system where increase of $90 \%$ of the tonic serotonin activity is expected after chronic SSRI treatment (Best et al., 2011). The result is also in accordance with the finding of increased amygdala neural response to happy faces after citalopram treatment in an fMRI study on healthy volunteers (Norbury et al., 2009). 
The $125 \%$ increase of the hidden-input amplitude after the four weeks citalopram treatment in our study is probably due to the evidenced a $75-80 \%$ decrease of serotonin reuptake transporters (SERT) binding site in the amygdala (Gould et al., 2003) and an internalization of SERT proteins from the cell surface, and redistribution of SERT from neurite extensions into the soma after a chronic SSRI treatment (Lau et al., 2008). A corollary of the result could be that depression associated with low hidden-input amplitude would be most effectively treated with a serotonegic agent (e.g. SSRI type antidepressant).

On the contrary, a weaker strengthening effect of citalopram on prolongation of the hiddeninput pulse in comparison with the effect of maprotiline and venlafaxin/clomipramine could suggest a noradrenergic nature of the parameter 'hidden-input pulse duration'. It follows that depression associated with short hidden-input pulse would be most effectively treated with a noradrenergic agent.

The strongest increasing effect on the FPFL and NFL gains was shown by venlafaxin and clomipramine (dual acting serotonin/noradrenaline agents). The finding that maprotiline has a weaker strengthening effect on the SPFL gain in comparison with both citalopram and venlafaxin/clomipramine could suggest that the last feedback loop in the SCR control system is more directly associated with the phasic serotonergic than with noradrenergic neurotransmission. Corollary of this would be that depression associated with weakened feedback loops' gains would be most effectively treated with a dual acting agent. There is also possibility to combine knowledge about hidden-input parameters and feedback loops' gains in selecting antidepressant for the treatment of an individual depressed patient.

\section{Limitations and future research}

The approach which we have proposed is supposed to enable an insight into the neural signaling of the monoaminergic systems through measuring and processing of the behavioral variables such as skin conductance response. Although the monoaminergic neural signaling is a net result of the subtle neurochemical processes such as neurotransmitters' release, reuptake, and receptor binding the present method does not allow a direct insight into the relationship between our estimations of the neural signaling and the pharmacological actions such as processes of down- or up-regulation of receptors, inhibition of transporters, and intracellular changes (Leonard, 2000). But there is a possibility to overcome this limitation of the present method. It could be done through an integration of the present model with the existing mathematical models of the cellular mechanisms of the dopaminergic and serotonergic signaling (Best et al., 2009; Best, Nijhout \& Reed, 2010; Best, Reed \& Nijhout, 2010; Best et al., 2011). The later models are models of the processes of synthesis, release, and reuptake of brainstem monoamines. Establishing the link between the SCR model and these models could bring to a deeper insight into the monoaminergic processes specifying the deviation in the processes through knowing the vales of the SCR system parameters. It could enable even more informed choice of psychotropic drugs (e.g. is it more appropriate to intervene with a postsynaptic receptor agent or with a drug acting on the reuptake transporters). Agreement between our findings on the change of SCR system's indicators of tonic and phasic monoaminergic functions due to serotonergic treatment, and theoretical assumptions derived from the model of serotonergic signaling (Best at al., 2011) render the task feasible. 
In this study we did not examine the effect of dopaminergic agents on the SCR system parameters what could be done in the future research. Further work could be also aimed to determine normative values of the hidden-input measures and the SCR system's parameters in larger samples of healthy individuals and to compare them with different populations of individuals currently experiencing an episode of a mental disorder.

\section{Conclusion}

In this contribution we introduced a methodological approach which appears promising for a possibility of establishing the bridge between the neurochemistry of the brain monoaminergic systems and psychophysiological measures such as skin conductance response. The SCR system in this perspective is viewed as a linear neurochemical oscillator suitable for mathematical modeling and estimation of the inherent control process. Through mathematical modeling of the SCR process two kinds of metrics emerged. One of them refers to the features of the hidden neural input for the SCR system generated in the amigdala-hippocamus interaction when an individual is encountered with an unexpected and significant stimulus. The other metrics specifies the regulatory (control system) aspect of the SCR process.

We presented the results of the first pharmacological intervention study aimed to reveal the neurochemical meaning of the parameters in the model of the SCR process. Future work on this issue could refine the method of the psychophysiological probing of the brain monoaminergic signaling systems and render it clinically applicable in: (1) the neurochemical characterization of an individual with a mental disorder and (2) a more informed choice of the psychotropic drugs for his or her treatment.

\section{Acknowledgment}

The author expresses great gratitude to Mr. Nenad Jeremić ("Blink N" Programming Agency) for the collaboration in development of the software tool for the automated analysis of the SCR signal. The publishing of the text was financially supported by ActavisSerbia.

\section{References}

Alexander, D.M., Trengove, C., Johnston, P., Cooper. T., August, J.P. \& Gordon, E. (2005). Separating individual skin conductance response in a short interstimulus-interval paradigm. Journal of Neuroscience Methods, Vol. 146, pp. 116-123.

American Psychiatric Association. (1994). Diagnostic and Statistical Manual of Mental Disorders. (the $4^{\text {th }}$ edition), American Psychiatric Association, Washington, DC.

Andreassi, J.L. (1989). Psychophysiology: Human Behavior and Physiological Response. Lawrence Erlbaum Associates Publishers, Hillsdale, New Jersey, pp. 217-221.

Aston-Jones, G., Ennis, M., Pieribone, V.A., Nickell, W.T. \& Shipley, M.T. (1986). The brain nucleus locus coeruleus: restricted afferent control of a broad efferent network. Science, Vol. 234, pp. 734-737. 
Bach, D.R., Flandin, G., Friston, K.J. \& Dolan, R.J. (2009). Time-series analysis for rapid event-related skin conductance responses. Journal of Neuroscience Methods, Vol. 184, pp. 224-234.

Bach, D.R., Friston, K.J. \& Dolan, R.J. (2010a). Analytic measures for quantification of arousal from spontaneous skin conductance fluctuations. International Journal of Psychophysiology, Vol. 76, pp. 52-55.

Bach, D.R., Flandin, G., Friston, K.J. \& Dolan, R.J. (2010b). Modelling event-related skin conductance responses. International Journal of Psychophysiology, Vol. 75, pp. 349-356.

Bach, D.R., Daunizeau, J., Kuelzow, N., Friston, K.J., \& Dolan R.J. (2011). Dynamic causal modeling of spontaneous fluctuations in skin conductance. Psychophysiology, Vol. 48, pp. 252-257, doi: 10.1111/j.1469-8986.2010.01052.x

Benedek, M., Kaernbach, C. (2010). Decomposition of skin conductance data by means of nonnegative deconvolution. Psychophysiology, Vol. 47, pp. 647-658.

Barry, R.J. (2006). Promise versus reality in relation to the unitary orienting reflex: A case study examining the role of theory in psychophysiology. International Journal of Psychophysiology, Vol. 62, pp. 353-366.

Bartova L., Berger A. \& Pezawas L. (2010). Is there a personalized medicine for mood disorders. Eur. Arch. Psychiatry Clin. Neurosci. Vol. 260, Suppl. 2, pp. S121-S126.

Best, J.A., Nijhout, H.F. \& Reed, M.C. (2009). Homeostatic mechanisms in dopamine synthesis and release: a mathematical model. Theoretical Biology and Medical Modelling, Vol. 6, Retrieved from URL: http://www.tbiomed.com/content/6/1/21

Best, J.A., Nijhout, H.F. \& Reed, M. (2010). Serotonin synthesis, release and reuptake in terminals: a mathematical model. Theoretical Biology and Medical Modelling, Vol. 7, Retrieved from URL: http:/ /www.tbiomed.com/content/7/1/34

Best, J., Reed, M. \& Nijhout, H.F. (2010). Models of dopaminergic and serotonergic signaling. Pharmacopsychiatry, Vol. 43, Suppl. 1, pp. S61-S66.

Best, J., Nijhout, H.F. \& Reed, M.C. (2011). Bursts and the efficacy of selective serotonin reuptake inhibitors. Pharmacopsychiatry, Vol. 44, Suppl. 1, pp. S76-S83.

Boyce, W.E. \& DiPrima, R.C. (2001). Elementary Differential Equations (7th edition), John Wiley \& Sons: New York, USA, p. 319.

Brandman, O., Ferrell, J.E., Li, R. \& Meyer, T. (2005). Interlinked fast and slow positive feedback loops drive reliable cell decisions. Science, Vol. 310, pp. 496-498.

Brandman, O. \& Meyer, T. (2008). Feedback loops shape cellular signals in space and time. Science, Vol. 322, pp. 390-395.

Branković, S. (2001). What have the sexual, the attachment, and the exploratory motivation in common?: The theory of informational needs. Psychiatria Danubina, Vol. 13, No. 1-4, pp. 31-43.

Branković, S.B. (2008). System identification of skin conductance response in depression - an attempt to probe the neurochemistry of limbic system. Psychiatria Danubina, Vol. 20, No. 3, pp. 310-322.

Branković, S. (2011). Interlinked positive and negative feedback loops design emotional sweating. Psychiatria Danubina, Vol. 23, No. 1, pp 10-20.

Breska, A., Maoz, K. \& Ben-Shakhar, G. (2011). Interstimulus intervals for skin conductance response measurement. Psychophysiology, Vol. 48, pp. 437-440. 
Buffalary, D.M. \& Grace A.A. (2007). Noradrenergic modulation of basolateral amygdala neuronal activity: opposing influences of $\alpha-2$ and $\beta$ receptor activation. (2007). Journal of Neuroscience, Vol. 27, No. 45, 12358-12366.

Charney, D.S., Bremner, J.D. \& Redmond D.E. (1995). Noradrenergic neural substrates for anxiety and fear: clinical associations based on preclinical research. In: Psychopharmacology: The Fourth Generation of Progress, Bloom, F.E. \& Kupfer, D.J. (Editors), pp. 387-395, Raven Press: New York.

Damasio, A,R. (1994). Descartes' Error. Emotion, Reason, and the Human Brain. Putnam Books, New York.

Dementienko, V.V., Dorokhov, V.B., Koreneva, L.G., Markov, A.G., Tarasov, A.V. \& Shakhnarovich, V.M. (2000). The hypothesis of the nature of electrodermal reactions. Human Physiology, Vol. 26, pp. 232-239.

Dunn, A.J., Swiergiel, A.H. \& Palamarchouk, V. (2004). Brain circuits involved in corticotropin-releasing factor - norepinephrine interactions during stress. Ann NY Acad Sci, Vol. 1018, pp. 25-34.

Edelberg, R. (1970). The information content of the recovery limb of the electrodermal response. Psychophysiology, Vol. 6, pp. 527-539.

Eggermont, J.J. (1998). Is there a neural code? Neuroscience \& Biobehavioral Reviews, Vol. 22, No. 2, pp. 355-370.

Exner, C., Boucsein, K., Degner, D., Irle, E. \& Weniger, G. (2004). Impaired emotional learning and reduced amygdala size in schizophrenia: a 3-month follow-up. Schizophrenia Research, Vol. 71, pp. 493-503.

Féré, C. (1888). Note sur des modifications de la résistance électrique sous l'influence des excitations sensorielles et des emotions. Comptes Rendus des Seances de la Societe de Biologie (Ser. 9), Vol. 5, pp. 217-219.

Fritschy, J.M., Lyons, W.E., Mullen, C.A., Kosofsky, B.E., Molliver, M.E. \& Grzanna, R. (1987). Distribution of locus coeruleus axons in the rat spinal cord: a combined anterograde transport and immunohistochemical study. Brain Research, Vol. 437, pp. 176-180.

Giorgi, F.S., Ferrucci, M., Lazzeri, G., Pizzanelli, C., Lenzi, P., Alessandri, M.G., Murri, L. \& Fornai, F. (2003). A damage to locus coeruleus neurons converts sporadic seizures into self-sustaining limbic status epilepticus. European Journal of Neuroscience, Vol. 17, No. 12, pp. 2593-2601.

Gould, G.G., Pardon, M.C., Morilak, D.A. \& Frazaer, A. (2003). Regulatory effects of reboxetine treatment alone, or following paroxetine treatment, on brain noradrenergic and serotonergic systems. Neuropsychopharmacology, Vol. 28, pp. 1633-1644.

Hadley, J.L. (1989). The neurobiology of motivational systems. In: Psychoanalysis and Motivation, Lichtenberg, J.D., pp. 337-372, The Analytic Press, Hove-London.

Hamilton, M. (1960). A rating scale for depression. Journal of Neurology, Neurosurgery $\mathcal{E}$ Psychiatry, Vol. 23, pp. 56-62.

Humble, M. (2000). Noradrenaline and serotonin reuptake inhibition as clinical principles: a review of antidepressant efficacy. Acta Psychiatrica Scandinavica, Vol. 101, Suppl. 402, pp. 28-36.

Kano, T., Inaba, Y. \& Avoli, M. (2005). Periodic oscillatory activity in parahippocampal slices maintained in vitro. Neuroscience, Vol. 130, pp. 1041-1053. 
Kepecs, A. \& Lisman, J. (2004). How to read a burst duration code. Neurocomputing, Vol. 5860, pp. 1-6.

Kim, D., Kwon, Y.K., Cho, K.H. (2006). Coupled positive and negative feedback circuits form an essential building block of cellular signaling pathways. BioEssays, Vol. 29, pp. 85-90.

Koch, C. (2005). Biophysics of Computation: Information Processing in Single Neurons, Oxford University Press, New York.

Koch, C., Rapp, M. \& Segev, I. (1996). A breaf history of time (constants). Cerebral Cortex, Vol. 6, No. 2, pp. 93-101.

Kumaran, D. \& Maguire, E.A. (2007a). Which computational mechanisms operate in the hippocampus during novelty detection. Hippocampus, Vol. 17, pp. 735-748.

Kumaran, D. \& Maguire, E.A. (2007b). Match-mismatch process underliy human hippocampal response to associative novelty. Journal of Neuroscience, Vol. 27, No. 32, pp. 8517-8524.

Kumaran, D. \& Maguire, E.A. (2008). Novelty signals: a window into hippocampal information processing. Trends in Cognitive Neuroscience, Vol. 13, No. 2, pp. 47-54.

Lader, M.H. (1980). The psychophysiology of anxiety. In: Handbook of Biological Psychiatry Part II: Brain Mechanisms and Abnormal Behavior Psychophysiology, Van Praag, H.M., Lader, M.H., Rafaelsen, O.J. \& Sachar, E.J. (Editors), pp. 225-247, Marcel Dekker, New York.

Laine, C.M., Spitler, K.M., Mosher, C.P. \& Gothard K.M. (2009). Behavioral Triggers of skin conductance response and their neural correlates in the primate amygdala. Journal of Neurophysiology, Vol. 101, April 2009, pp. 1749-1754.

Lau, T., Horschitz, S., Berger, S., Bartsch, D. \& Schloss, P. (2008). Antidepressant-induced internalization of the serotonin transporter in serotonergic neurons. FASEB J, Vol. $22,1702-1714$.

LeDoux, J.E. (1992). Emotion and amygdala. In: The Amygdala: Neurobiological Aspects of Emotion, Memory, and Mental Dysfunction, Aggleton J.P. (Editor), pp. 339-351, WileyLiss, New York.

Leonard, B. (2000). Clinical implications of mechanisms of action of antidepressants. Advances in Psychiatric Treatment, Vol. 6, pp. 178-186.

Lestienne, R. (2001). Spike timing, synchronization and information processing on the sensory side of the central nervous system. Progress in Neurobiology, Vol. 65, pp. $545-591$.

Lewis, M.D. (2005). Bridging emotion theory and neurobiology through dynamic systems modeling. Behavioral and Brain Sciences, Vol. 28, No. 2, pp. 169-245.

Lim, C.L., Gordon, E., Rennie, C., Wright, J.J., Bahramali, H., Li, W.M., Clouston, P. \& Morris, J.G.L. (1999). Dynamics of SCR, EEG, and ERP activity in an oddball paradigm with short interstimulus intervals. Psychophysiology, Vol. 36, pp. 543-551.

Ljung, L. (1999). System Identification - Theory for the User (second edition), Prentice Hall, Upper Saddle River, N. J.

Lodge, D.J. \& Grace, A.A. (2006). The hippocampus modulates dopamine neuron responsivity by regulating the intensity of phasic neuron activation. Neuropsychopharmacology, Vol. 31, pp. 1356-1361.

Luppi, P.H., Aston-Jones, G., Akaoka, H., Chouvet, G. \& Jouvet, M. (1995). Afferent projections to the rat locus coeruleus demonstrated by retrograde and anterograde 
tracing with cholera-toxin B subunit and Phaseolus vulgaris leucoagglutinin. Neuroscience, Vol. 65, pp. 119-160.

Masuda, N. \& Aihara, K. (2007). Dual coding hypotheses for neural information representation. Mathematical Bioscience, Vol. 207, pp. 312-321.

Mishkin, M. \& Aggleton, J. (1981). Multiple functional contributions of the amygdala in the monkey, In: The Amygdala Complex, Ben-Ari, Y. (Editor), pp. 409-420, Elsevier/North Holland, New York.

Mössner, R. et al. (2007). Consensus paper of the WFSBP task force on biological markers: biological markers in depression. World Journal of Biological Psychiatry, Vol. 8, No. 3, pp. 141-174.

Nicoll, R.A., Madison, D.A., Lancaster, B. (1987). Noradrenergic modulation of neuronal excitability in mammalian hippocampus. In: Psychopharmacology: The Third Generation of Progress, Meltzer, H.Y. (Editor), pp. 105-112, Raven Press, New York.

Norbury, R., Taylor, M.J., Selvaraj, S., Murphy, S.E., Harmer, C.J. \& Cowen, P.J. (2009). Short-term antidepressant treatment modulates amygdala response to happy faces. Psychopharmacology, doi: 10.1007/s00213-009-1597-1

Nutt, D. (2008). Relationship of neurotransmitters to the symptoms of major depressive disorder. Journal of Clinical Psychiatry, Vol. 69, Suppl. E1), pp. 4-7.

Nutt, D., Demyttenaere, K., Janka, Z., Aarre, T., Bourin, M., Canonico, P.L., Carrasco, J.L. \& Stahl, S. (2007). The other face of depression, reduced positive affect: the role of catecholamines in causation and cure. Journal of Psychopharmacology, Vol. 21, No. 5, pp. 461-471.

O'Gorman, J.G. (1971). Habituation of the orienting reaction as a function of stimulus information. Psichonomic Science, Vol. 22, pp. 331-332.

Pape, H.C., Narayanan, R.T., Smid, J., Stork, O. \& Seidenbecher, T. (2005). Theta activity in neurons and networks of the amygdala related to long-term fear memory. Hippocampus, Vol. 15, pp. 874-880.

Paré, D. \& Gaudreau, H. (1996). Projection cells and interneurons of the lateral and basolateral amygdala: distinct firing patterns and differential relation to theta and delta rhythms in conscious cats. Journal of Neuroscience, Vol. 16, No. 10, pp. 33343350 .

Pfaff, D., Westberg, L. \& Kow, L.M. (2005). Generalized Arousal of Mammalian Central Nervous System. Journal of Comparative Neurology, Vol. 493, pp. 86-91.

Phelps, E.A. (2004). Human emotion and memory: interactions of the amygdala and hippocampal complex. Current Opinion in Neurobiology, Vol. 14, pp. 198-202.

Pfeuty, B. \& Kaneko, K. (2009). The combination of positive and negative feedback loops confers exquisite flexibility to biochemical switches. Physical Biology, Vol. 6, pp. 46013, doi: 10.1088/1478-3975/6/4/046013

Phillips, A.G., Ahn, S. \& Howland, J.G. (2003). Amygdalar control of the mesocorticolimbic dopamine system: parallel pathways to motivated behavior. Neuroscience and Biobehavioral Reviews, Vol. 27, pp. 543-554.

Rainnie, D.G. (1999). Serotonergic modulation of neurotransmission in the rat basolateral amygdala. Journal of Neurophysiology, Vol. 82, pp. 69-85.

Redgrave, P., Gurney, K. \& Reynolds, J. (2008). What is reinforced by phasic dopamine signals? Brain Research Reviews, Vol. 58, pp.322-339. 
Reyes, B.A., Valentino, R.J., Xu, G. \& Van Bockstaele, E.J. (2005). Hypothalamic projections to locus coeruleus neurons in rat brain. European Journal of Neuroscience, Vol. 22, pp. 93-106.

Salgado-Pineda, P., Delaveau, P., Blin, O. \& Nieoullon, A. (2005). Dopaminergic contribution to the regulation of emotional perception. Clinical Neuropharmacology, Vol. 28, pp. 228-237.

Shadlen, M.N. \& Newsome, W.T. (1998). The variable discharge of cortical neurons: implications for connectivity, computation, and information coding. Journal of Neuroscience, Vol. 18, pp. 3870-3896.

Schätze, I., Knuepfer, M.M., Eismann, A., Stumpf, H. \& Stock, G. (1987). Sensory input to single neurons in the amygdala of the cat. Experimental Neurology, Vol. 97, pp. 499515.

Segal, M. \& Bloom, F.E. (1976). The action of norepinephrine in the rat hippocampus. IV. The effects of locus coeruleus stimulation on evoked hippocampal activity. Brain Research, Vol. 107, pp. 513-525.

Seidenbecher, T., Laxmi, T.R., Stork, O. \& Pape, H.C. (2003). Amygdalar and hippocampal theta rhythm synchronization during fear memory retrieval. Science, Vol. 301, pp. 846-850.

Stein, C., Davidowa, H. \& Albrecht, D. (2000). 5-HT1A receptor-mediated inhibition and 5$\mathrm{HT}_{2}$ as well as $5-\mathrm{HT}_{3}$ receptor-mediated excitation in different subdivisions of the rat amygdala. Synapse, Vol. 28, pp. 328-337.

Takahashi, H., Yahata, N., Koeda, M., Takano, A., Asai, K., Suhura, T. \& Okubo, Y. (2005). Effects of dopaminergic and serotonergic manipulation on emotional processing: a pharmacological fMRI study. Neuroimage, Vol. 27, pp. 991-1001.

Tarchanoff, J. (1890). Über die galvanischen Erscheinungen an der Haut des Menschen bei Reizung der Sinnesorgane und bei verschidenen Formen der psychischen Tätigkeit. Pflügers Archiv für die gesammte Physiologie des Menschen und der Tiere, Vol. 46, pp. 46-55.

Tsai, T.Y.C., Choi, Y.S., Ma, W., Pomerening, J.R., Tang, C. \& Ferrell J.E.Jr. (2008). Robust, tunable biological oscillations from interlinked positive and negative feedback loops. Science, Vol. 321, pp. 126-129.

Tyler, C.W. \& Likova, L.T. (2011). Estimating neural signal dynamics in the human brain. Frontiers in Systems Neuroscience, Vol. 5, Article 33, doi: 10.3389/fnsys.2011.00033

Valentino, R.J. \& Aston-Jones, G.S. (1995). Physiological and anatomical determinants of locus coeruleus discharge. Behavioral and clinical implikations. In: Psychopharmacology: The Fourth Generation of Progress, Bloom, F.E. \& Kupfer, D.J. (Editors), pp. 373-385, Raven Press: New York.

Van Bockstaele, E.J., Pieribone, V.A. \& Aston-Jones, G. (1989). Diverse afferents converge on the nucleus paragigantocellularis in the rat ventrolateral medulla: retrograde and anterograde tracing studies. Journal of Comparative Neurology, Vol. 290, No. 4, pp. 561-584.

Varela, F., Lachaux, J.P., Rodriguez, E. \& Martinerie, J. (2001). The brainweb: phase sinchronization and large-scale integration. Nature Neuroscience, Vol. 2, pp. 229-239.

Venables, P.H. \& Christie, M.J. (1980). Electrodermal activity. In: Techniques in Psychophysiology, Martin, I. \& Venables, P.H. (editors), pp. 3-67, John Wiley \& Sons, Chichester, New York, Brisbane, Toronto. 
Vigoroux, R. (1879). Sur le role de la resistance electrique des tissues dans l'electrodiagnostic. Comptes Rendus Societe de Biologie, Vol. 31, pp. 336-339.

Vigoroux, R. (1888). The electrical resistance considered as a clinical sign. Progres Medicale, Vol. 3, pp. 87-89.

Vinogradova, O.S. (1975). The hippocampus and the orienting reaction. In: Neuronal Mechanisms of the Orienting Reflex, Sokolov, E.N. \& Vinogradova, O.S. (editors), pp. 183-215, Lawrence Erlbaum Associates Publishers, Hillsdale, NJ.

Wanat, M.J., Willuhn, I., Clark, J.J. \& Phillips, P.E.M. (2009). Phasic dopamine release in appetitive behaviors and drug addiction. Current Drug Abuse Reviews, Vol. 2, No. 2, pp. 195-213.

Yamamoto, R., Ueta, Y. \& Kato, N. (2007). Dopamine induces a slow afterdepolarization in lateral amygdala neurons. Journal of Neurophysiology, Vol. 98, pp. 984-992.

Zhang, X.P., Cheng, Z., Liu, F. \& Wang, W. (2007). Linking fast and slow positive feedback loops creates an optimal bistable switch in cell signaling. Physical Review, Vol. 76, pp. 031924, doi: 10.1103/PhysRevE.76.031924 


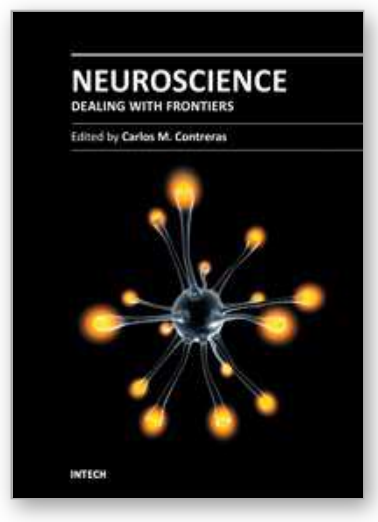

\author{
Neuroscience - Dealing With Frontiers \\ Edited by Dr. Carlos M. Contreras
}

ISBN 978-953-51-0207-6

Hard cover, 440 pages

Publisher InTech

Published online 16, March, 2012

Published in print edition March, 2012

The Neuronal Doctrine recently reached its 100th year and together with the development of psychopharmacology by the middle of 20th century promoted spectacular developments in the knowledge of the biological bases of behavior. The overwhelming amount of data accumulated, forced the division of neuroscience into several subdisciplines, but this division needs to dissolve in the 21 st century and focus on specific processes that involve diverse methodological and theoretical approaches. The chapters contained in this book illustrate that neuroscience converges in the search for sound answers to several questions, including the pathways followed by cells, how individuals communicate with each other, inflammation, learning and memory, the development of drug dependence, and approaches to explaining the processes that underlie two highly incapacitating chronic degenerative illnesses.

\title{
How to reference
}

In order to correctly reference this scholarly work, feel free to copy and paste the following:

Saša Branković (2012). Assessment of Brain Monoaminergic Signaling Through Mathematical Modeling of Skin Conductance Response, Neuroscience - Dealing With Frontiers, Dr. Carlos M. Contreras (Ed.), ISBN: 978-953-51-0207-6, InTech, Available from: http://www.intechopen.com/books/neuroscience-dealing-withfrontiers/assessment-of-brain-monoaminergic-signaling-through-mathematical-modeling-of-skin-conductancerespon

\section{INTECH}

open science | open minds

\section{InTech Europe}

University Campus STeP Ri

Slavka Krautzeka 83/A

51000 Rijeka, Croatia

Phone: +385 (51) 770447

Fax: +385 (51) 686166

www.intechopen.com

\section{InTech China}

Unit 405, Office Block, Hotel Equatorial Shanghai

No.65, Yan An Road (West), Shanghai, 200040, China

中国上海市延安西路65号上海国际贵都大饭店办公楼405单元

Phone: +86-21-62489820

Fax: $+86-21-62489821$ 
(C) 2012 The Author(s). Licensee IntechOpen. This is an open access article distributed under the terms of the Creative Commons Attribution 3.0 License, which permits unrestricted use, distribution, and reproduction in any medium, provided the original work is properly cited. 